\title{
Eukaryotic algae populated the tropical ocean 1400million years ago
}

SHUICHANG ZHANG ${ }^{1}$, JINSU ${ }^{1}$, SIHONG MA ${ }^{1}$, HUAJIAN WANG ${ }^{1}$, XIAOMEI WANG ${ }^{1}$, KUN $^{1}$ HE $^{1}$, DONALD E. CANFIELD ${ }^{1,2}$

${ }^{1}$ Research Institute of Petroleum Exploration and Development, Beijing, 100083, China

${ }^{2}$ Department of Biology and Nordcee, University of Southern Denmark, Campusvej 55, 5230 Odense M, Denmark

Correspounding author: sczhang@petrochina.com.cn

The Proterozoic Eon bridged the prokaryote-dominated Archean Eon with the animal-dominated Phanerozoic Eon, and thus saw the rise of eukaryotic ecosystems including those populated by eukaryotic algae. Algae are relatively large, and their emergence may have responded to increased nutrient and oxygen availability in the oceans while also acting to enhance ocean oxygenation, generating a permissive environment for animals. Thus, emergence of algal ecosystems may have acted as both a barameter and driver of Earth-surface chemical change. The fossil record indicates that eukaryotic algae evolved by the late Paleoproterozoic Era. However, the biomarker record of steranes does not reveal their presence until the middle of the Cryogenian Period, suggesting that eukaryotic algae were insignificant ecosystem members for some one billion years after they evolved.

We conducted high-temperature pyrolysis of kerogen from the $1400 \mathrm{Ma}$ Xiamaling Formation, a well-preserved, low maturity, Mesoproterozoic-aged strata. A host of lipid molecules were liberated, including $\mathrm{C}_{27}$ to $\mathrm{C}_{29}$ steranes, indicating the presence of red and green algae. Our results seem to couple the geochemical biomarker record with the fossil record of eukaryotes, suggesting that eukaryotes were widespread in the Mesoproterozoic oceans. Their influence on marine ecology and on the carbon cycle still needs to be evaluated, but at least to a limited degree, they likely contributed to accelerated particle export into the deep oceans, beginning the approach to Phanerozoic Eon-style carbon cycling. Eukaryotic algae could have come to prominence through the rise of grazing eukaryotic protists, preferentially grazing cyanobacteria from the water column. Furthermore, such grazers would have produced fast-sinking organic detritus, producing an even more vigorous carbon cycle that could have oxygenated the upper ocean.

Thus, the marine ecosystem at $1400 \mathrm{Ma}$ housed eukaryotic algae that actively contributed to primary production. Our results shed light on the timing of the emergence of algal marine ecosystems and the nature of ocean and atmosphere chemistry at $1400 \mathrm{Ma}$. 